\title{
Design and Develop CMS for Sindhi E-News Papers
}

\author{
Rasool Bux Palh', Haque Nawaz ${ }^{2, *}$, Zubair Ahmed Shaikh² and Asif Ali Wagan² \\ ${ }^{1}$ IICT, Mehran University of Engineering and Technology, Jamshoro, Pakistan; hnlashari@smiu.edu.pk \\ 2Department of Computer Science, Sindh Madressatul Islam University Karachi, Pakistan; rasoolbuxp@gmail.com, \\ zubair@smiu.edu.pk, asif.wagan@smiu.edu.pk
}

\begin{abstract}
Objective: To design and Develop CMS for Sindhi e-newspaper by using the searching techniques. Methods/analysis: Existing e-newspapers are not implementing any CMS with searching techniques. The research methodology is supposed to b experimental. A web CMS is developed for Sindhi e-newspaper by using the following tools/technologies: JavaServer Faces, MYSQL and Apache Tomcat. Findings: All news material is set at the server in the Sindhi language and information is rendered precisely on account of the Unicode support. Novelty/improvement: Structured Web Content Management System is easy to understand that gives the news thing classifications. The web-based interface is accessible to peruse neighborhood news like Kawish, Express, and Dawn that are not much easy to understand and every substance is accessible in the picture group just as a composed substance that is the reason there is no scanning module to look for specific news things. We have organized and built up an application for neighborhood newspapers and provided a checking module to look for a required substance of the news content. The looking is unfathomably astoundingly smart since Apache Lucene is working at rear close during interest.
\end{abstract}

Keywords: CMS, Apache Lucene, HTML, API, JCP, JVM

\section{Introduction}

Data is a perceived piece of information. Information is likewise a significant asset of an association. $\frac{1}{}$ A particular executive framework is a bunch of necessary information and gathering of projects to get to that information. The accumulation of information called databases that have data with respect to an association. The main objective of datum is to give an advantageous and proficient approach to store and bring database information. Datum frameworks are made to deal with huge data. Information the executives include contains both clarifying stockpiling structure and control system of data.

- The datum framework must be secured,

- Facts provided to be kept securely,

- To be kept away from framework strikes,

- To stop the Unsanctioned attack.

It is to keep away from conceivable irregular outcomes when information is divided. The database is a basic piece of each undertaking. The development of the web clients straightforwardly attack to datum through the web interface and accomplishes different tasks on the datum. In spite of the fact that Web interface or UI conceals the detail of datum get to and the majority of individuals don't know that they are associating with the database and play out specific activities on a certain data. $\frac{2}{2}$

The Internet has been broadening over the world too and up to this point, has been utilized for the most part by the administration research centers, colleges, and protection contractual workers and after that, it ends up as the internet. Internet is an enormous appropriated framework that is stage free and archives are concatenated, not sequential machine-readable text, illustrations, sound and video records over the Internet. There are a large number of sites are accessible and developing step by step. Composing and perusing of new techniques are given by the machine-readable text, which uses a PC upheld position. Machine-readable text design comprises illustrations, sound, content, and video. It additionally

${ }^{*}$ Author for correspondence 
contains the connections to interface different hubs and gives characteristics those aides in layout configuration, screen arrangements, and connections. All data is rendered as machine-readable text on the internet that is gained utilizing HTM. $\underline{3}$ Because of the development of registering innovation, the programming application accessibility is searched in each association to decrease human endeavors and furthermore to give an answer for professional applications. There are several programming dialects for the product application improvement however Java is prevalent among them. The Java EE stage is the arrangement of administrations, runtime conditions, and conventions to structure multi-layered, dependable and versatile mesh-based applications. In multi-layered applications, the waged of application is isolated into separate viable zones, known as layered.

- Multi-layered application contains:

- Client level,

- Middle level,

- Enterprise data level or information level .

In Java Enterprise applications advancement, the center level is the foundation of a complete framework to form applications more secure and vigorous. Java Enterprise Edition stage gives numerous MVC structures to create endeavor application..,$\underline{4}$

JAVA SE: It indicates essential sorts of cutting edge classes and the Java stage is utilized in different requisitions. Counting to center API, Java Standard Edition is a stage that gives a JVM, applications advancement structures, organization innovations and numerous libraries and toolboxes regularly utilized in Java applications. Java is an article arranged, basic, stage free, structural unbiased, hearty, compact and multithreaded, elite, disseminated and dynamic programming language. $\underline{6}$

JavaServer Faces: It is an acknowledged structure to manufacture appealing GUI for electronic applications that give a quick application advancement condition for alluring graphical UIs that is really one of the most critical and irritating pieces of Web application improvement. In any case, it is feasible to make graphical UIs with the assistance of useful Java Web-based advancements. There is no broad system created for big business application improvement, these center advancements can prompt upkeep and improvement issues and JSF illuminates every issue in an institutionalized manner. Java Community Process created JavaServer Faces by a relationship of innovation suppliers including Oracle and IBM alongside a gathering of Java and Web geeks that are well known in the product business. $?$

JavaServer Faces innovation contains the following:

- An Application program interfaces for depicting segments and to deal with their state; occasions taking care of, approval customer and server-side, and information transformation; to characterize route; bolsters availability and internationalization; and gives extensibility to every one of these highlights.

- Intrinsic faceless, that supports progressed UI templating.

- Pleasant Ajax support.

- Compound things.

- Real approval with coordinated beans (JSR 303).

- Pleasant support for different assets.

- Uncomplicated improvement condition.

Prime Faces: A famous UI structure for JavaServer Faces, utilized to build up venture applications with rich UI parts for a standard site. Prime countenances have:

- Affluent set of segments (Html Editor, Dialog, AutoComplete, Charts and significantly more).

- AJAX-based center segments.

- Peeling Framework.

Eclipse IDE: It depends upon stage having shared office and stretch module framework for the most part utilized for programming application improvement.

MySQL: It is social datum, the board framework works on organized inquiry language. It can be utilized generally in all scope of uses either that are work area based or electronic applications.

JDBC API: It gives a managed path for databasefree correspondence among Java-based applications and game plan of datums such as SQL database, disallowed information source, spreadsheets, and level records. JDBC gives call level API to get to the SQL-based database. You are allowed to utilize JDBC API in Java programming language to achieve "Make Once, Run Anywhere" viability for applications to get to enormous business data. JDBC is an innovation empowered driver that gives an answer for interface venture information additionally in heterogeneous condition..

APACHE Tomcat: It is a programming application that gives execution to Java-based applications. Java Community Process creates particulars of advance Java EE. Apache Tomcat is the group up a delayed consequence 
of the world's best originators. It is used to have the web order and try system..,$\underline{10}$

Data, information, learning, and substance are the equivalent word term of one another, yet each has precise importance which gap one structure other. There are four ideas known as grammatical forms, the information shows the solitary words, data is a determination, content is additionally a determination however it in a particular setting, learning is the situation of mind that is perused, heard and comprehended by an individual. So as to make and deal with an undertaking learning, the Content Management System (CMS) is a fantastic answer to oversee data. Despite the fact that there are many perplexities in regards to the functionalities that depicts CMS and about changes with lower-performing items like archives and record the board frameworks, Web content administration frameworks and undertaking content administration frameworks. Content Management is one of the instruments that is actualized by big business to deal with their data. It gives a standard of methodologies and strategies to gather, oversee and distribute the substance. It robotizes the procedure of substance arrangement, overseeing and distributing with the assistance of data innovations. It likewise gives the command over substance creation and appropriation. $\underline{11}$

There are three stages in the Content Management System as appeared in Figure 1.

- Collection System

- Management System

- Publication System

These stages are covered and carefully worked with one another.

\subsection{Collection System}

This framework relies upon apparatuses, strategies, and HR that need to get substance and oversaw in the second

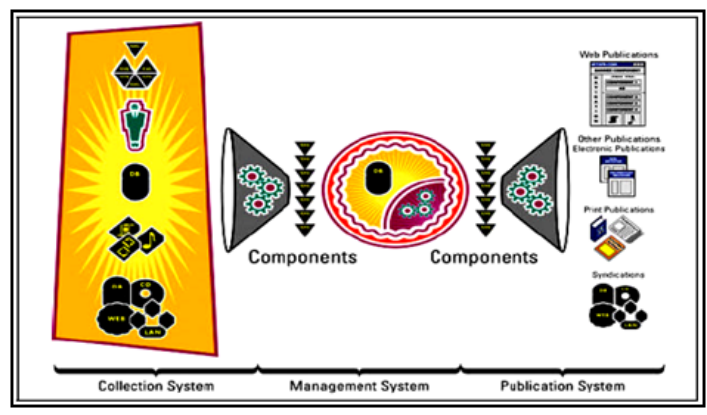

Figure 1. Circuit of content management system. stage. The procedure included is: In the composing process, every one of the substances is composed by the creator in an appropriate manner. The procurement procedure gives an approach to get the required information as indicated by need like news things for papers. During the transformation procedure, we are fundamentally changing the substance in a legitimate request and convert into appropriate data. In the Aggregation process, every one of the substances is collected that gives the office to the next procedure. The last procedure accumulation benefits essentially give the administrations to gather the substance and those substances are passed by specific techniques and projects to get required substance and data. $\underline{11}$

\subsection{Management System}

The information is appropriately gathered and after that administration, the framework is essential to store content, to discover content, arrangement a similar substance and metadata assembled in the initial step of the lifecycle. The storehouse, organization and work process capacity are given by the framework that encourages one to know which of the substance-related to an association. 11

\subsection{Publication System}

The publication framework concentrates substance from the executive's framework's storehouse and convert it for definite distribution, named for an outside client, yet additionally for an association that imparts inside. The produced outcomes could be electronic or any print including online interfaces.

\subsection{Features Comparison of Various CMS}

To depict the most legitimate substance the board framework in a specific setting, we have acknowledged the way of making a rundown of required highlights. To study and execute includes in the above examined five substance the executive's frameworks. The initial step to choose the CMS as per the criteria.

Specialized necessities talked about CMSs are appeared in Figure 2. Breaks down the CMSs on specific highlights and their accessibility, each element consists of one of accompanying qualities that are: $\checkmark$ (indeed, present), $\times$ (actually no, not present), ${ }^{\star}$ (accessible free add on), (present however restricted use). $\underline{12}$ 


\section{Materials and Methods}

\subsection{Designed CMS and Application Flow}

We are giving web content organization system to e-papers in which substance are written in neighborhood tongues like Sindhi and Urdu. We have moreover given a glance through strategies to examine inside the news substance for explicit information. The news online interfaces that are analyzed as of now in which the Kawish web news passageway working with pictures just and the interface isn't much engaging anyway the substance are genuine and intelligible. The Kawish paper contains picture altering handiness yet has no journey convenience to find for explicit substance, the follower has the experience to see the whole information of all the papers. The Urdu language is used for the substance in express news electronic interface, the proper data is used in the news portal and has a present news slider to invigorate update

\begin{tabular}{|c|c|c|c|c|c|c|}
\hline Categories & Features & Alfersco & $\overline{\text { Drupal }}$ & Wordperss & Joomla & DotNetNuke \\
\hline \multirow[t]{4}{*}{ Security } & Versioning & $\checkmark$ & $\checkmark$ & - & $\checkmark$ & $\checkmark$ \\
\hline & Email & $\checkmark$ & $\checkmark$ & $\checkmark$ & $\checkmark$ & $\checkmark$ \\
\hline & Captcha & $\bullet$ & $\checkmark$ & $\checkmark$ & $\cdot$ & $*$ \\
\hline & $\begin{array}{l}\text { Login } \\
\text { history }\end{array}$ & $\checkmark$ & $\checkmark$ & $\checkmark$ & $\checkmark$ & $\checkmark$ \\
\hline \multirow[t]{4}{*}{ Performance } & Load & $\checkmark$ & $\checkmark$ & $\checkmark$ & $\checkmark$ & $x$ \\
\hline & $\begin{array}{l}\text { Static } \\
\text { content }\end{array}$ & $\bullet$ & $\checkmark$ & $\checkmark$ & $x$ & $x$ \\
\hline & Page Cache & $\checkmark$ & $\checkmark$ & $\checkmark$ & $\checkmark$ & $\checkmark$ \\
\hline & Database & $\bullet$ & $\checkmark$ & $x$ & - & $\checkmark$ \\
\hline \multirow[t]{3}{*}{ Support } & Online Help & $\checkmark$ & $\checkmark$ & $\checkmark$ & $\checkmark$ & $\checkmark$ \\
\hline & Third Party & $\checkmark$ & $\checkmark$ & $\checkmark$ & $\checkmark$ & $\checkmark$ \\
\hline & $\begin{array}{l}\text { Pluggable } \\
\text { API }\end{array}$ & $\checkmark$ & $\checkmark$ & $\checkmark$ & $\checkmark$ & $\checkmark$ \\
\hline \multirow{10}{*}{$\begin{array}{l}\text { Built-In } \\
\text { Features }\end{array}$} & Contact & $\cdot$ & $\cdot$ & $\checkmark$ & $\bullet$ & $\checkmark$ \\
\hline & Blog & $\bullet$ & $\bullet$ & $\checkmark$ & $\checkmark$ & $\checkmark$ \\
\hline & Chat & $\bullet$ & $\bullet$ & $\checkmark$ & $\cdot$ & $\cdot$ \\
\hline & FAQ's & $\cdot$ & $\bullet$ & $\checkmark$ & $\checkmark$ & $\checkmark$ \\
\hline & News letter & $\checkmark$ & $\checkmark$ & $\checkmark$ & $\cdot$ & $\checkmark$ \\
\hline & Pools & $\cdot$ & $\cdot$ & $\checkmark$ & $\checkmark$ & $\checkmark$ \\
\hline & Search & $\cdot$ & $\checkmark$ & $\checkmark$ & $\checkmark$ & $\checkmark$ \\
\hline & Wila & $\bullet$ & $\checkmark$ & $\checkmark$ & $\bullet$ & $\checkmark$ \\
\hline & Survey & $\bullet$ & $\cdot$ & $\checkmark$ & $\cdot$ & $\checkmark$ \\
\hline & Data Entry & $\checkmark$ & $\checkmark$ & $\checkmark$ & $\bullet$ & $\checkmark$ \\
\hline \multirow[t]{3}{*}{ Management } & Clip Board & $\checkmark$ & $\checkmark$ & - & $x$ & * \\
\hline & Advertising & $\bullet$ & • & $\checkmark$ & $\bullet$ & $\checkmark$ \\
\hline & Asset & $\checkmark$ & $\checkmark$ & $\checkmark$ & $\checkmark$ & $\checkmark$ \\
\hline \multirow[t]{7}{*}{ Ease of Use } & Mass upload & $\cdot$ & $\checkmark$ & $\checkmark$ & $\cdot$ & $\checkmark$ \\
\hline & Site set up & & $\checkmark$ & $x$ & - & $\checkmark$ \\
\hline & $\begin{array}{l}\text { Spell } \\
\text { Checker }\end{array}$ & $\checkmark$ & $\checkmark$ & $\bullet$ & $\cdot$ & $x$ \\
\hline & Templates & $\checkmark$ & $\checkmark$ & $\checkmark$ & - & - \\
\hline & Undo & $\checkmark$ & $\checkmark$ & - & - & $\checkmark$ \\
\hline & $\begin{array}{l}\text { Drag and } \\
\text { Drop }\end{array}$ & $\bullet$ & $\checkmark$ & $\checkmark$ & $\bullet$ & $x$ \\
\hline & Zip archives & $\bullet$ & $\checkmark$ & $\checkmark$ & $x$ & $x$ \\
\hline
\end{tabular}

Figure 2. Feature comparison of various CMS. news things. The application UI is extraordinary and is fittingly supervised at this point it doesn't urge the follower to filter for a particular or related substance as shown by interest. The daybreak news online interface has a decent application design to deal with the substance it has the two highlights like news picture and furthermore news composed substance. It gives a looking through office yet now and then the outcomes are not legitimate as indicated by the hunt. The entire application is great and appropriately made do with alluring UI and such different functionalities.

\subsection{The Architecture of Designed}

\section{Application}

By utilizing open principles 3-level engineering given by Sun-like Java EE, Java Servlets, JSP and Java Persistence API as appeared in Figure 3.

- Persistence Layer.

- Business Layer.

- Presentation Layer.

\subsubsection{Persistence Layer}

This layer associated with datum and acts as unfaltering quality assignments like DML operations. The assignments are known as CRUD assignments. In this application, JDBC API is being used to connect with the datum.

\subsubsection{Business Layer}

This layer contains all the basics of web application value. The helpfulness could be starting a money move of thing

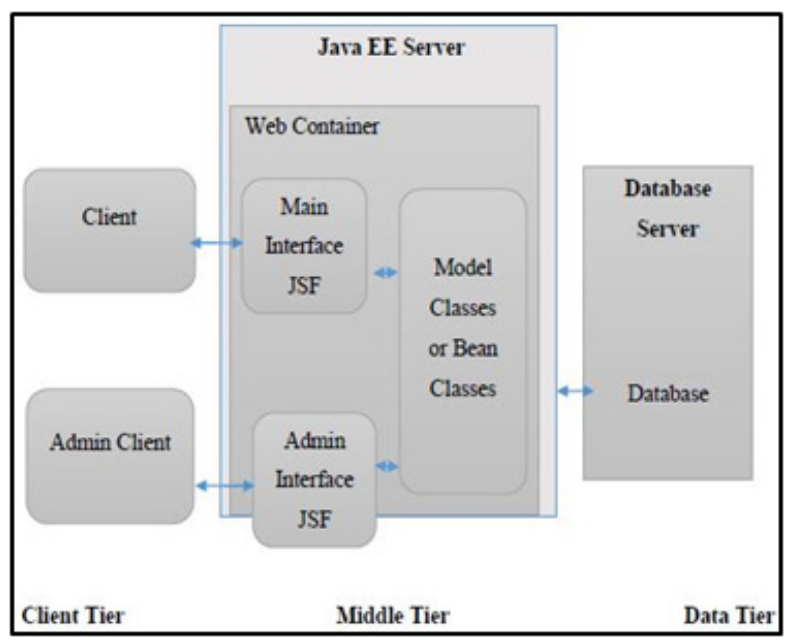

Figure 3. Web CMS application architecture. 
on-site using a charge card. Cause another customer, to drop a customer or register after the effect of battle in a Web game.

\subsubsection{Presentation Layer}

This layer is accountable for GUI that express the opinion to the customer by delivering HTML pages, enduring customer information using GET and POST method techniques.

\subsection{Database Schema}

Database formation demonstrates a legitimate perspective on the entire database that characterizes how to sort out the information and connection between them. It characterizes every limitation that is to be implemented by information. A datum development delineates the substances and association in the middle of them. It has an unmistakable particular of datum that can be appeared by strategies for example. Datum framework is organized by datum makers that possible for designers to understand the datum and to build that datum important. The datum has three tables used in Web CMS application for instance classes, papers, and customers. Classes and papers table have one to various associations as showed up in Figure 4.

At the point when a student fills the educator's assessment structure totally, the whole instructor's connected information stacks on the server. At that point an exceed expectations report is created on the server which contains the evaluating size of each educator of the particular office which is as of now being chosen by the administrator. The exceed expectations report makes exact and advanced data of the instructor.

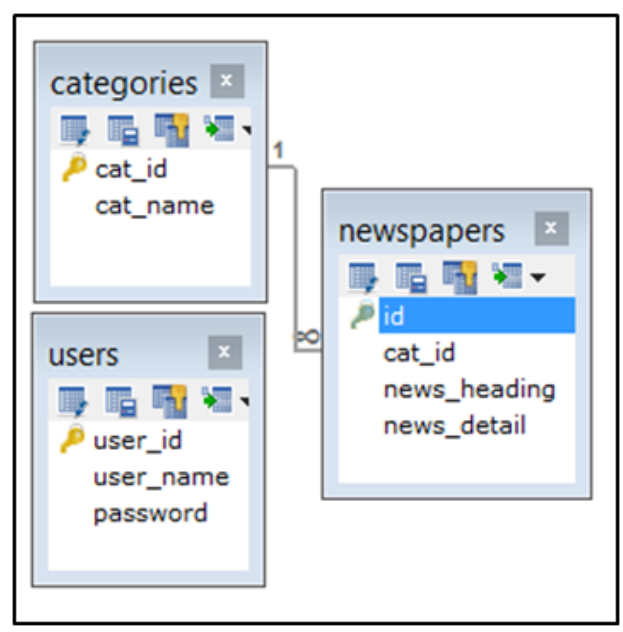

Figure 4. Database schema.

\subsection{Searching Experiments}

The innovation utilized for looking is Apache Lucene that is an unsecured origin and complete-content glancing through advancement. Java sort of Lucene has been used in this application, anyway it offers Application Program Interface to other schedule vernaculars. To recoup onceover of reports that contest definite standards. So the looking at for a particular book is essential, in light of the way that the looking through can be conceivable by utilizing the title, writer, distributor and year of coursing. The outcomes should be possible in a feasible manner on the grounds that the above quires can be enough overseen in a social database. If there should arise an occurrence of normal datum the foul information of the report is dealt with into the tuples so the looking can't be reasonably managed to utilize social database solicitation to look through information competently.

In the full content inquiry, the web crawler needs to filter the majority of the expressions of the content record, and attempt to coordinate a few criteria against it, for example, discover certain words or expressions in its substance. That sort of inquiries in an exemplary social datum will be miserable.

\subsection{Searching and Indexing}

Apache Lucene gives a speedy hunt reaction cause is that it glance through a rundown instead of glimpsing inside the substance genuinely. The document-based glancing through capacities as we are sifting for specific words in page utilizing records, that reports are accessible at the back of the book. So these sorts of the archive are known as changed records since it changes a page-driven information structure (page $->$ words) to a watchword is driven information structure (word $->$ pages).

It contains, pivoted records do it the other course around. For each word in the narratives, you have a quick overview of the vast majority of reports that contain that term. That is monstrously dynamically gainful when performing full substance pursues.

Exemplary record: 49

Record 1 gooing, to, jump, into, Apache, Lucene, rich, open, source, full, content, search...\}

Archive 2 \{so, must, wonder, Lucene, can accomplish, exceptionally, quick, full, content, search, not...\}

Archive 3 rreason that, rearranged, file, work, great, can be, seen...\}

Altered list: 
1 reason $\{(3,0)\}$

2 Lucene $\{(1,6),(2,4)\}$

3 full $\{(1,10),(2,9)\}$

4 going $\{(1,0)\}$

5 record $\{(3,3)\}$

6 pursuit $\{(1,11),(2,10)\}$

\subsubsection{Single Word Search}

We are checking for a news thing as shown by that specific watchword and the result are as showed up in Figure 5. That exhibits the number of glanced through evidence, glanced through catchphrase is peaked inside such substance.

In this search, a watchword is a dispatch to the glancing through limit around then the record is made into the

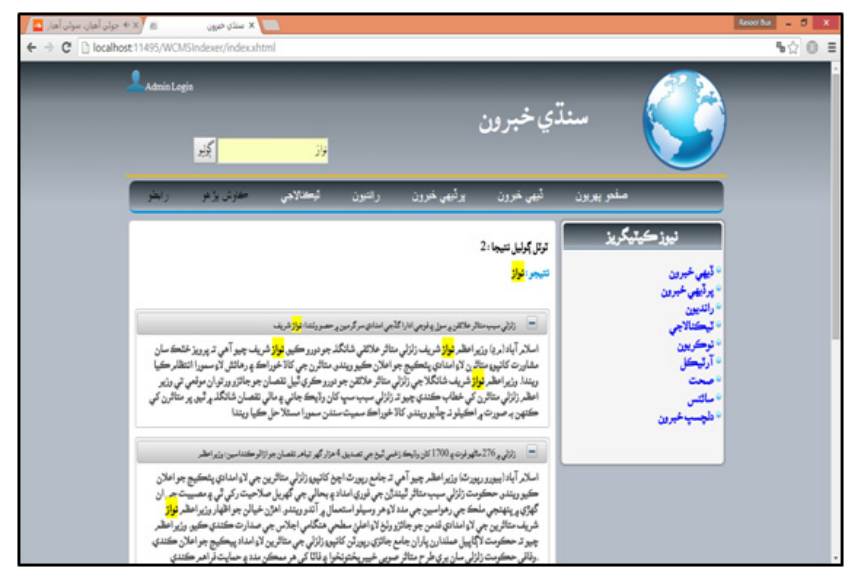

Figure 5. Single-word searching view.

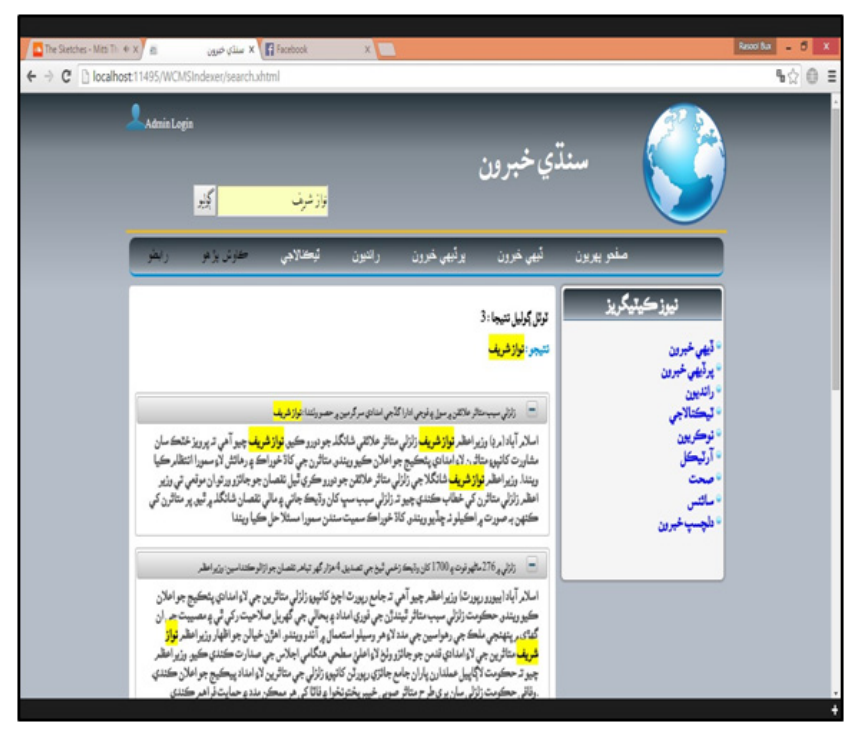

Figure 6. Word-pair searching view. arranged inventory those rundown are adjusted rundown. The document holds the estimation of each word into the record archive after that peering is accomplished inside rundown reports.

This search is used in looking for a news thing as shown by word pair and the consequence is showed up in Figure 6.

It shows the full-scale amount of glanced through records, glanced through catchphrase is also peaked inside that substance.

\subsubsection{Phrase search}

Phrase search shows that we are looking for a news thing into state and the consequence is as showed up in Figure 7. It expresses indisputably the quantity of glanced through evidence, glanced through watchword is also peaked inside that substance.

If the specific articulation isn't available in the substance, by then code breaks the articulation in work tokens and a short time later brings substance for each token.

\section{Results and Discussion}

Plan and execution issues identified with usage of Java Enterprise Edition innovation, probably the greatest test when wanted. A portion of the basic issues can be experienced when programming designers are actualizing a gigantic IT framework. It is an obligation of programming draftsmen and JEE designer to appropriately comprehend the conditions that a customer needs and give legitimate arrangements that meet the creating business needs as well as build up a long haul dependable and adaptable framework. $\underline{13}$

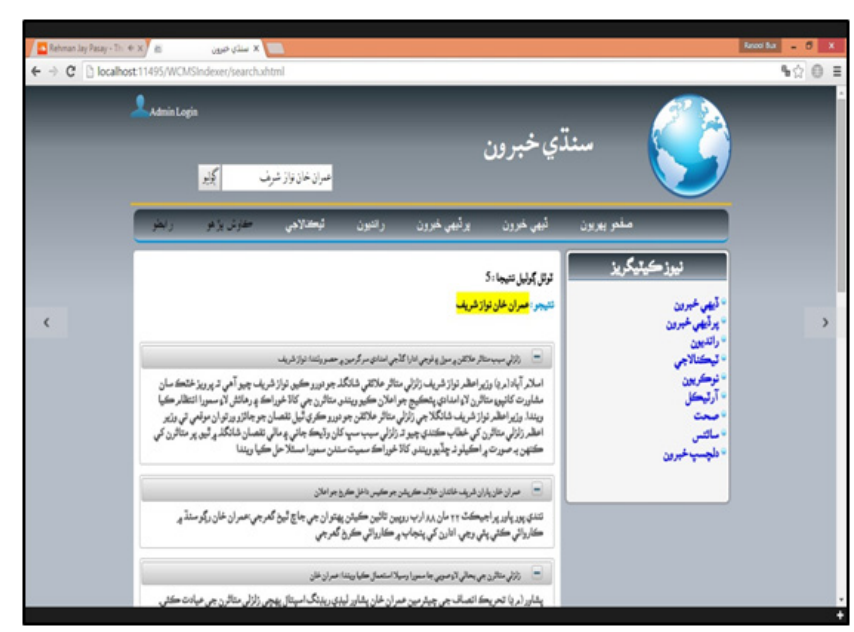

Figure 7. Phrase searching view. 
Concentrate on the looking and information is developing step by step and execution of looking can be appeared in Figure 8.

Figure. 8 shows that the they-pivot exhibits the reaction time in the seconds and $\mathrm{x}$-hub shows the number of evidence that is rising bit by bit. It allows the reaction time throughout the course of examining related news things. During the request in light of a legitimate concern for the word all the related evidence is glanced through either a watchword is available in news heading or in news nuances.

Figure. 9 shows that the they-pivot exhibits the reaction time in the seconds and $\mathrm{x}$-hub shows the number

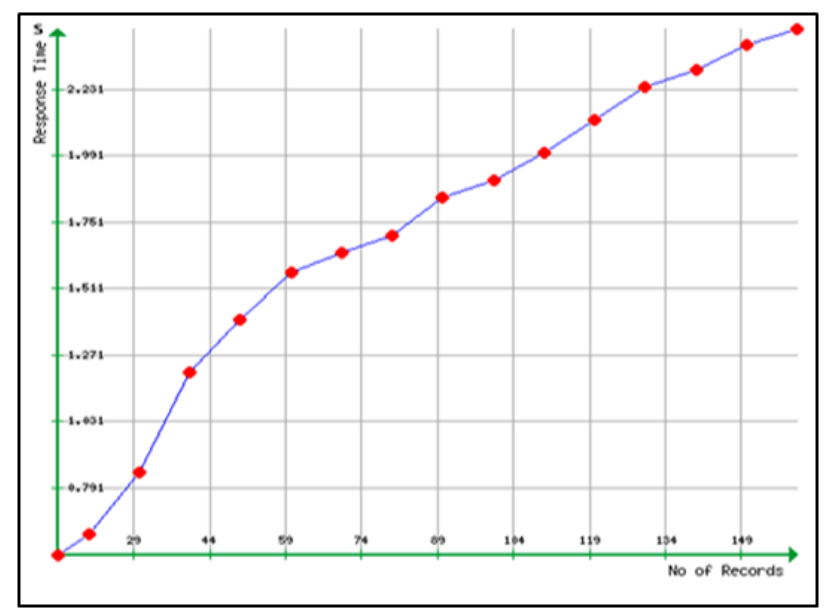

Figure 8. Searching performance graph in terms of a single-word.

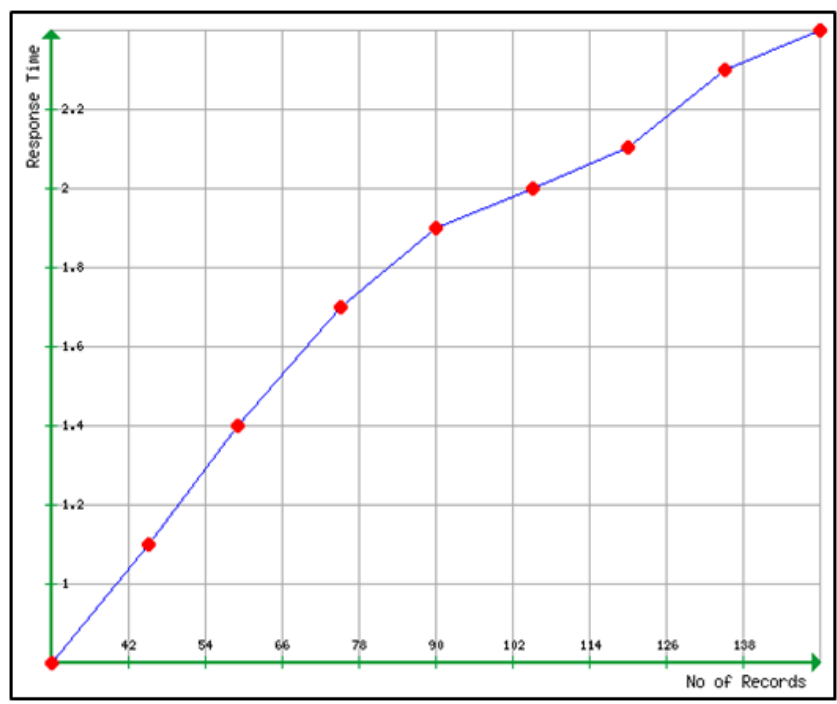

Figure 9. Searching performance graph in terms of word-pair. of evidence. It exhibits the reaction time during the searching for related news things. During the request in light of a legitimate concern for the word pair, all the related evidence is glanced through either a word pair is open in the news heading or in news nuances.

Figure 10 shows that the they-pivot exhibits the reaction time in the seconds and $\mathrm{x}$-hub shows the number of evidence. It exhibits the reaction time during the filtering for related news things. During the interest to assist the articulation all evidence glances through either an articulation in the news heading or in news nuances.

By and by a day's typically every affiliation proceeds towards the advancement either the administrator's structure, chronicles or e-4news doorways and significantly more. Every affiliation proceeds from the physical system to networked structures by utilizing web developments. Our assessment issue also related to online interface phenomenally planned for e-news passages. In the case of Kawish news entrance, it gives an online web substance to the news per user and electronic interface contains news pictures that are the reason checking for a particular news thing is unbelievable by using any catchphrase. So the per user needs to encounter all the paper for a particular news thing.

In the event that there ought to emerge an event of Express news gateway which contains the news thing that is open in the database so the looking is exceptionally basic by using social inquiries. Regardless, Express news passageway has no looking value to filter for particular news things.

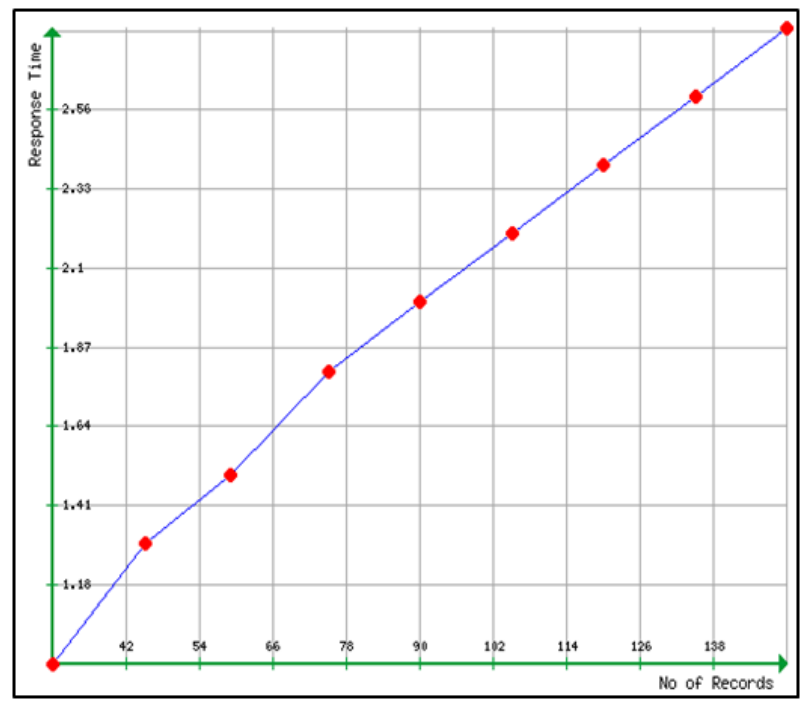

Figure 10. Searching performance graph in terms of phrase search. 
The Dawn news passage is a combo of the Kawish and Express news door it has substance in a sort of pictures and besides created substance in the database. It has a glancing through handiness that is gives the results at explicit criteria yet on occasion the required results are not authentic and looking isn't successful to the extent time.

\subsection{Comparison of Web CMS with Other News Web Portals}

The designed Web CMS is increasingly secure, in spite of the fact that it oversaw appropriately regarding information getting with rich UI. The progression of the application is working legitimately for each situation for example as far as looking, information bringing, and information refreshing. All the data is put away in a database in a legitimate way on the grounds that the database has Unicode support.

At the opposite part of the bargain, Express news gateway doesn't give any looking alternative to scan for a specific substance. That is the reason there is have to structure a Web CMS that beat the looking through issues and the looking through outcomes must be exceptionally quick when contrasted with social database inquiries.

\section{Achievements}

Every one of the destinations accomplished effectively and targets are:

- Design and make Web CMS for Sindhi e-papers.

- Provide glancing through options.

- Design glancing through a technique to glance through the substance in the e-paper or e-magazine capably.

In the delayed consequences of targets we gain the perfect point that is:

Implementation of Web CMS using JEE for close by e-paper like Sindhi.

\section{Conclusion}

In this paper, an organized application, an authentic e-news online interface for the Sindhi language has been developed. The movement of an application remains in an enduring state. We are giving more noteworthy helpfulness when diverged from other neighborhood language e-news electronic interfaces. No other e-news online interfaces have glancing through value. The looking should be conceivable on explicit criteria and the glancing through results are inconceivably incredibly snappy in light of the way that glancing through limit uses indexer based looking. Every one of the records is made into the rundown index. Those records are disturbed rundown so looking is staggeringly incredibly fast take an abundance of less time. This application has engaging UI with straightforward conditions. We have arranged the Web CMS by using the latest JEE edge work.

\section{References}

1. Boston university 2012 graduate student library survey report. [cited 2012 Sep]. http://www.bu.edu/library/files/2 012/09/2012GraduateStudentLibrarySurveyReport.pdf.

2. Kroenke, DM, Auer D. Database concepts. Prentice Hall Press; 2014. https://www.amazon.com/ Database-Concepts-7th-David-Kroenke/dp/01335446213.

3. Hirsch PM. Exercise the power of the world wide web. IEEE Comput Appl Power. 1995;8:25-29.

4. Building java enterprise applications: architecture. [cited 2002 Mar 28]. https://www.amazon.com/ Building-Java-Enterprise-Applications-Architecture/dp/ B0091MGMFK.

5. Overview of enterprise applications - your first cup: an introduction to the Java EE platform. [cited 2012]. https:// docs.oracle.com/javaee/6/firstcup/doc/gcrky.html.

6. Java: the complete reference. [cited 2017 Jul 01]. https://www. amazon.in/Java-Complete-Reference-Herbert-Schildt/ dp/9339212096.

7. JavaServer Faces 2.0, the complete reference. [cited 2010 Apr 24]. https://www.amazon.in/Javaserver-Faces-20-Complete-Reference/dp/0070703477.

8. Ivanov S, Carson JH. Database connectivity. In: New Perspectives on Information Systems Development: Theory, Methods, and Practice (eds. Harindranath, G. et al.) 449-460 (Springer US, 2002). doi:10.1007/978-1-4615-0595-2_37.9.

9. Pro Apache Tomcat 6. [cited 2007 Mar 23]. https://www. amazon.com/Pro-Apache-Tomcat-Matthew-Moodie/ dp/1590597850.

10. Apache Tomcat ${ }^{\oplus}$ - Welcome! [cited 2019] http://tomcat. apache.org/.

11. Benevolo C, Serena N. Evaluation of Content Management Systems (CMS): a Supply Analysis. Electronic Journal of Information Systems Evaluation. 2007;10:9-21.

12. Mirdha A, Jain A, Shah K. Comparative analysis of open source content management systems. In: 2014 IEEE international conference on computational intelligence and computing research; 2014. P. 1-4.

13. Building scalable and high-performance java web applications using J2EE technology. [cited 2001 Dec 27]. https://www.amazon.in/Building-ScalableHigh-Performance-Applications-Technology/ dp/0201729563. 